\title{
Simulation of Dry Reforming of Methane to Form Synthesis Gas as Feed Stock for Acetic Acid Production
}

\author{
Intan Clarissa SoPHIANA ${ }^{1}$, Tri Partono AdHI ${ }^{1}$, and Yogi Wibisono BUdHI ${ }^{1, *}$ \\ ${ }^{1}$ Department of Chemical Engineering, Faculty of Industrial Technology, Institut Teknologi Bandung, Bandung, 40132, Indonesia
}

\begin{abstract}
The Natuna gas field is one of the largest natural gas reserves in Indonesia with estimated natural gas reserves of 222 TCF. However, until now, the use of Natuna gas is still hampered because of the very high $\mathrm{CO}_{2}$ content reaching $71 \%$, while the methane content is around $28 \%$. The dry reforming of methane (DRM) process is one of the potential ways to be applied for solving these problems to convert $\mathrm{CH}_{4}$ and $\mathrm{CO}_{2}$ to synthesis gas containing $\mathrm{CO}$ and $\mathrm{H}_{2}$ as a raw material that can be applied to manufacture as intermediate products or end products in the petrochemical industry such as acetic acid. The simulation of the acetic acid production was conducted by using ASPEN HYSYS v.10, considering mass and heat balances. The PengRobinson was applied for dry reforming of methane process. In order to produce $496.8 \mathrm{kmol} / \mathrm{h}$ of the acetic acid, the $500 \mathrm{kmol} / \mathrm{h}$ for each $\mathrm{CH}_{4}$ and $\mathrm{CO}_{2}$ were used as feed gas. The total energy required is 4.7 MMBtu per ton of acetic acid. The acetic acid has a purity of $99.4 \%$ with a concentration of $500 \mathrm{ppm}$ methanol, and moisture content of $5,700 \mathrm{ppm}$.
\end{abstract}

\section{Introduction}

The Natuna gas field is one of the biggest natural gas reserves in the world with estimated natural gas reserves of 222 TCF. However, until now, Natuna gas utilization is still hampered due to the high $\mathrm{CO}_{2}$ content, which reaches $71 \%$. With only $28 \%$ of methane content, the use of Natuna natural gas requires a thorough and comprehensive technical study (Sumartono, 2000). This high $\mathrm{CO}_{2}$ content when discharged into the air after fed purification can increase greenhouse gases, so the high amount of $\mathrm{CO}_{2}$ needs to be processed into a useful product. The method of utilizing natural gas generally uses reforming technology which can convert natural gas into synthesis gas. Reforming technologies include steam reforming, partial oxidative reforming, and dry reforming (Balasubramanian et al., 2018).

Dry reforming of methane (DRM) technology is one of the potential ways to be applied in answering these problems. The concept of the DRM process is reacting $\mathrm{CH}_{4}$ and $\mathrm{CO}_{2}$ to produce synthesis gas containing $\mathrm{CO}$ and $\mathrm{H}_{2}$ as a raw material that can be applied to manufacture as intermediate products or end products in the petrochemical industry such as acetic acid (Knifton, 1985). In Indonesia, the need for acetic acid increases every year and reached 101,787 tons/year in 2015. The conversion of carbon dioxide and methane to acetic acid is carried out in three stages. The first step, $\mathrm{CO}_{2}$ and $\mathrm{CH}_{4}$ are reformed to produce the synthesis gas. The second step, the synthesis gas is converted to produce methanol. The last step, the acetic acid is produced by reacting methanol and $\mathrm{CO}$ in the methanol carbonylation process.
The DRM reaction is reversible and endothermic, so it requires considerable energy to maintain operating conditions. In addition, this DRM reaction requires a high operating temperature to achieve maximum equilibrium conversion and minimize carbon deposition on the catalyst. The methanol production to synthesis gas is reversible and exothermic, so it requires high pressure and low temperature to achieve maximum equilibrium conversion. The methanol carbonylation process to produce acetic acid is an exothermic reaction.

The DRM process consists of four main reactions: DRM (1), reverse water gas shift reaction (2), Boudouard reaction (3), and $\mathrm{CH}_{4}$ decomposition (4) (Abdulrasheed et al., 2019; Foppa et al., 2016). The methanol synthesis occurs via three reactions: hydrogenation of carbon monoxide (5), hydrogenation of carbon dioxide (6), and water gas shift reaction (7) (Graaf et al., 1988; Richardson and Paripatyadar, 1990). The acetic acid production occurs via methanol carbonylation process (8) (Jarrell and Gates, 1975).

Dry Reforming of Methane

$\mathrm{CO}_{2}+\mathrm{CH}_{4} \rightleftarrows 2 \mathrm{CO}+2 \mathrm{H}_{2}$

$\mathrm{CO}_{2}+\mathrm{H}_{2} \rightleftarrows \mathrm{CO}+\mathrm{H}_{2} \mathrm{O}$

$2 \mathrm{CO} \rightleftarrows \mathrm{CO}_{2}+\mathrm{C}_{(\mathrm{s})}$

$\mathrm{CH}_{4} \rightleftarrows 2 \mathrm{H}_{2}+\mathrm{C}_{(\mathrm{s})}$

Methanol Synthesis

$2 \mathrm{H}_{2}+\mathrm{CO} \rightleftarrows \mathrm{CH}_{3} \mathrm{OH}$

$\mathrm{CO}_{2}+3 \mathrm{H}_{2} \rightleftarrows \mathrm{CH}_{3} \mathrm{OH}+\mathrm{H}_{2} \mathrm{O}$

$\mathrm{CO}+\mathrm{H}_{2} \mathrm{O} \rightleftarrows \mathrm{CO}_{2}+\mathrm{H}_{2}$

Acetic Acid Synthesis

$\mathrm{CH}_{3} \mathrm{OH}+\mathrm{CO} \rightleftarrows \mathrm{CH}_{3} \mathrm{COOH}$

\footnotetext{
* Corresponding author: Y.Wibisono@che.itb.ac.id
} 


\section{Research Method}

This research focused on the calculation of acetic acid production from $\mathrm{CO}_{2}$ and $\mathrm{CH}_{4}$ using process simulation by ASPEN HYSYS v.10 software and applied for 496.8 $\mathrm{kmol} / \mathrm{h}$ capacity.

\subsection{Basis simulation}

The acetic acid production from $\mathrm{CO}_{2}$ was simulated by using Aspen HYSYS v.10. Peng-Robinson Fluid Package was used as a base in the process of forming synthesis and methanol gas, as well as the UNIFAC Fluid Package in the process of forming acetic acid from methanol. These bases were chosen to estimate the liquid phase equilibrium and gas (VLE) system of acetic acid production. The model was built by considering the following considerations.

- Product specifications could be seen in Table 1.

- Steady state operating system.

- No energy lost in the system.

- The pressure drops in the reactor for dry reforming of methane, methanol formation, and acetic acid formation were set to $0.4 \mathrm{bar}, 1 \mathrm{bar}$, and 0.8 bar.

- The DRM reactor used had a length of $10 \mathrm{~m}$, a diameter of $0.2 \mathrm{~m}$, and 1500 tubes were used in the simulation.

Table 1. Acetic acid specification

\begin{tabular}{cc}
\hline Describe & Specification \\
\hline Purity, minimum & $99.3 \%$ \\
Methanol, maximum & $500 \mathrm{ppm}$ \\
Water, maximum & $6,000 \mathrm{ppm}$ \\
$\begin{array}{c}\text { Impurity organic, } \\
\text { maximum }\end{array}$ & $100 \mathrm{ppm}$ \\
\hline
\end{tabular}

\subsection{Process simulation}

The process was described in three stages. The flow diagram of this process is shown in Figure 1.

\subsubsection{Synthesis Gas Formation Process (PFR-100)}

Gas feed (stream 3 ) was the result of the mixing process (MIX-100) of $\mathrm{CO}_{2}, \mathrm{CH}_{4}$, and recycled gas from the separation process (V-100). The feed mixture which had a temperature of $375^{\circ} \mathrm{C}$ and 1.5 bar pressure conditions was preheated to reach the reaction temperature in the dry reforming of methane which was $900^{\circ} \mathrm{C}$ by using heat exchanger (E-102). At this temperature, the formation of carbon was quite small so that it could be ignored. Feed gas, then entered the reactor (PFR-100) with nickelalumina catalyst so it could be converted to synthesis gas with reaction kinetics following the equation used by Luyben (2014). The kinetics were as follow.

$$
\begin{aligned}
r_{F} & =k_{1} \exp \left(\frac{-50 \frac{k J}{\mathrm{~mol}}}{R T}\right) P_{\mathrm{CH} 4} P_{\mathrm{CO} 2} \\
r_{R} & =k_{-1} \exp \left(\frac{-195,9 \frac{k J}{\mathrm{~mol}}}{R T}\right) P_{\mathrm{CO}} P_{\mathrm{H} 2} \\
r_{\text {Rev WGSR }} & =k_{2} \exp \left(\frac{-50 \frac{k J}{\mathrm{~mol}}}{R T}\right) P_{\mathrm{CO} 2} P_{\mathrm{H} 2}
\end{aligned}
$$

The reactions that occurred in this process were endothermic. This was intended to enlarge the heat transfer surface area on the reactor wall. The reactor output component was composed of $\mathrm{CO}, \mathrm{H}_{2}, \mathrm{H}_{2} \mathrm{O}$ results from the reverse WGSR, and $\mathrm{CO}_{2}$ and $\mathrm{CH}_{4}$ as remaining unconverted feeds. The output had a temperature of $910^{\circ} \mathrm{C}$ and a pressure of 1 bar and could be used to heat the feed into the reactor (PFR-100).

Fifty percent of the CO component in output gas was separated and bypassed as a feed for the manufacture of acetic acid which would go through treatment first. The process of separating $\mathrm{CO}$ gas from other gases used a Pressure Swing Adsorption (PSA) unit at a pressure of 1 bar and a temperature of $401^{\circ} \mathrm{C}$. This synthesis gas output had a temperature of $48^{\circ} \mathrm{C}$, most of the gas would flow to the next process there was the formation of methanol.

\subsubsection{Methanol Formation Process (ERV-100)}

In the process of forming methanol, the pressure of synthesis gas that had been produced in the previous unit must be increased from 1 bar to 50.5 bar by using a compressor $(\mathrm{K}-100)$ and lowered the temperature to $150^{\circ} \mathrm{C}$ using a heat exchanger (E-106) and cooler (E-100). Synthesis gas with suitable feed conditions then entered a copper-zinc-alumina-based reactor (ERV-100) which had a pressurized water cooler, where the coolant would take heat from the reaction to form HP steam. Overall, these reactions were exothermic which produced. The pressure of reactor outflow contained methanol and other components then lowered by expander (VLV-101) from 49.5 bar to 3.5 bar, then flowed to the cooling unit (E-101) to lower the temperature to $50^{\circ} \mathrm{C}$ before entering the separator for separating the gas fraction and liquid fraction. Some of the gas that had been reduced in pressure and the temperature would be condensed to become liquid (especially methanol and water). The result of condensation with a pressure condition of 3 bar and a temperature of $30^{\circ} \mathrm{C}$ was separated in a two-phase separator $(\mathrm{V}-100)$. The separated gas fraction then was recycled back to the reactor as a reactant for the process of forming synthesis gas.

\subsubsection{Acetate Acid Formation Process (CRV-100)}

In the process of forming acetic acid, methanol from the previous process in liquid conditions was mixed (MIX103) with carbon monoxide feed from the stream 7 . The pressure of $\mathrm{CO}$ gas feed that was bypassed in the first stage was increased to 3.5 bar using a compressor (K-101). The feed temperature in the form of methanol and carbon monoxide were increased to $\pm 175^{\circ} \mathrm{C}$ by using a heat exchanger (E-106) to achieve operating conditions which was a temperature of $175^{\circ} \mathrm{C}$ and a pressure of 2.5 bar. 
Then the feed entered the reactor (CRV-100), which operated continuously under these conditions. The reactor worked isothermally. The catalyst used was a rhodium complex. The reaction in the reactor was exothermic which produces the heat. The heat of the reaction produced was absorbed using cooling water that entered at room temperature into the cooling jacket. Carbon monoxide and methanol were reacted in the liquid-gas phase.

The temperature of the reaction product in the form of gas was lowered so that it reached a temperature of around $30^{\circ} \mathrm{C}$ using a cooler (E-104). The reactor output product which had been lowered in temperature then was separated between the liquid phase and the gas phase (X101). The gas resulted from the separation were fed back into the reactor by $80 \%$ to react with methanol, while $20 \%$ was purged. The results of the bottom separation, which was a liquid phase with compositions of $\mathrm{H}_{2} \mathrm{O}, \mathrm{CH}_{3} \mathrm{OH}$, $\mathrm{CH}_{3} \mathrm{COOH}$ was fed to the distillation column (T-101) and separated under the conditions of a feed pressure of around 2 bar and a temperature around $35^{\circ} \mathrm{C}$. In the process of purifying the product by using a distillation column, the top results were in the form of unreacted reactants (methanol) and a little $\mathrm{H}_{2} \mathrm{O}$ that out of the distillation column at a pressure of 1.5 bar and a temperature of $75^{\circ} \mathrm{C}$. The top results were then re-flowed using a pump (P-100) as a reactor feed so it could be reacted again. Meanwhile, the product under the distillation column in the form of product (acetic acid) had a purity of $>99.3 \%$ according to product specifications in Table 1. Acetic acid products were then cooled with cooler (E-105) to reach room temperature before entering the storage tank of acetic acid product.

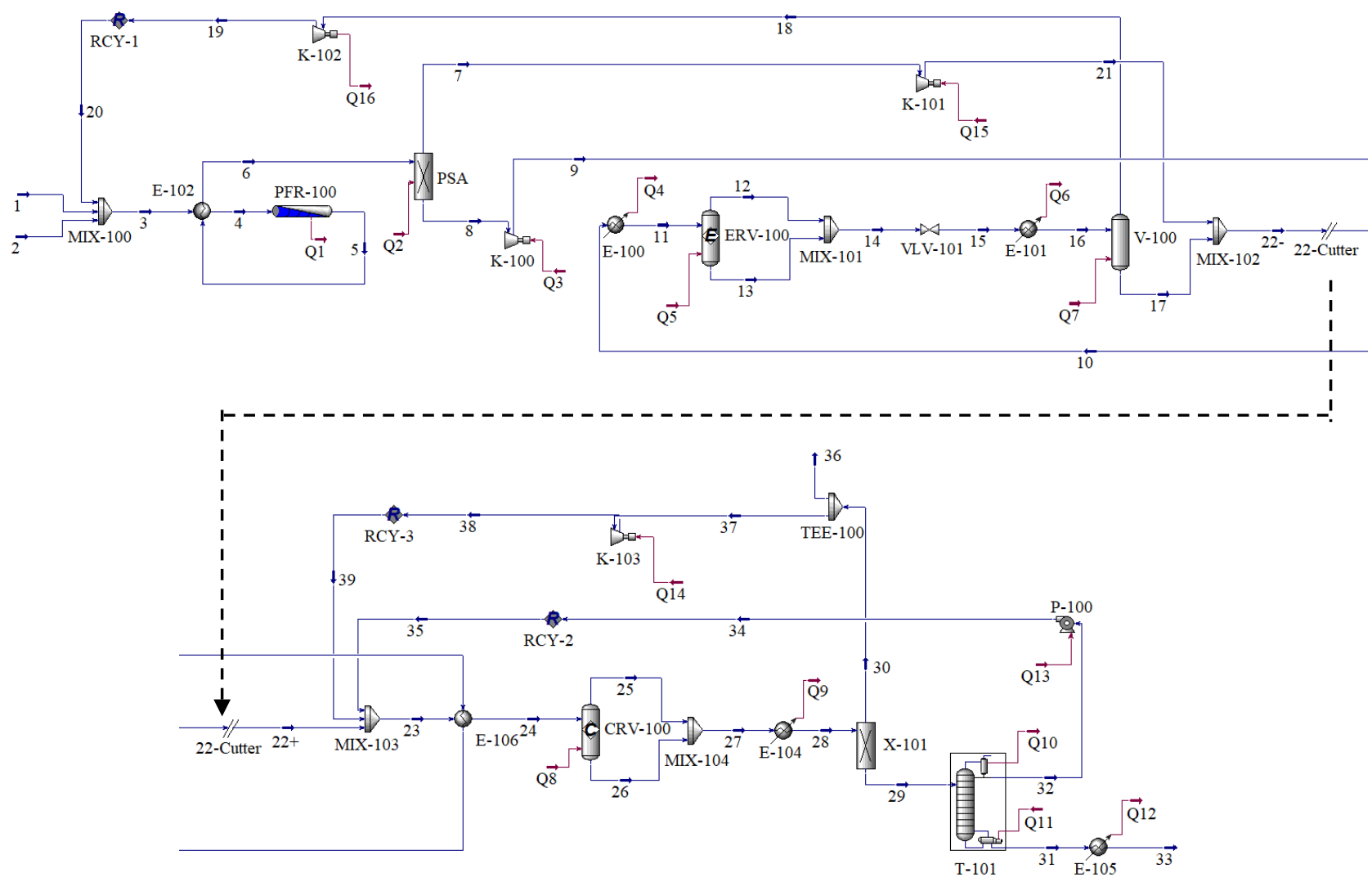

Figure 1. Process flowsheet of acetic acid production from $\mathrm{CO}_{2}$ and $\mathrm{CH}_{4}$ using the developing model in ASPEN HYSYS

\section{Results and Discussion}

\subsection{Thermodynamic analysis}

The Gibbs energy $(\Delta G)$ can be used as a reference for the spontaneity of a reaction. The smaller Gibbs energy $(\Delta G<0)$, the more spontaneous a reaction can take place. The Gibbs energy of each reaction at various temperatures in the synthesis gas formation and methanol formation can be seen in Figures 2 and 3.
In the synthesis gas formation, the increase of reaction temperature will make the dry reforming of methane reaction take place spontaneously. Meanwhile, the Boudouard reaction occurs when the reaction temperature is low. At temperatures above $900^{\circ} \mathrm{C}$, the dry reforming of methane reaction occurs more spontaneously than the reverse WGSR, Boudouard reaction, and $\mathrm{CH}_{4}$ decomposition.

In the reaction of methanol formation from $\mathrm{CO}$ and $\mathrm{H}_{2}$, the increase of reaction temperature will reduce the spontaneous of the reaction. So, the reaction of the methanol formation from synthesis gas is preferred at lower temperatures. 


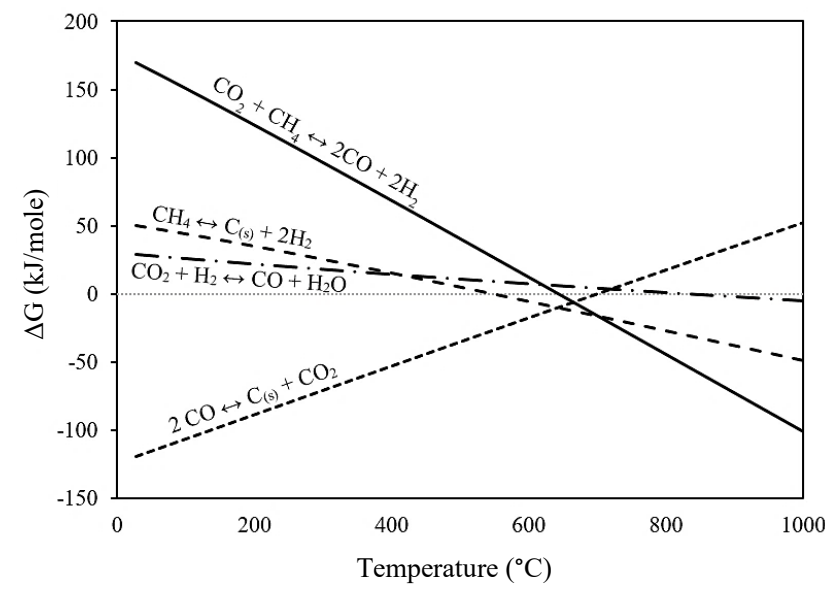

Figure 2. The Gibbs energy in the reaction of the synthesis gas formation

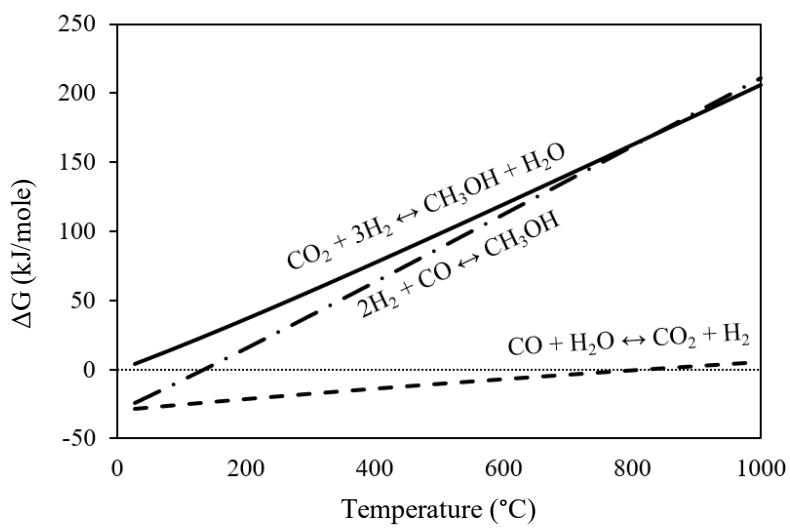

Figure 3. The Gibbs energy in the reaction of the methanol formation

\subsection{Reactor model}

The reaction unit was used for the production of acetic acid from $\mathrm{CO}_{2}$ and $\mathrm{CH}_{4}$ consists of three reactors, including the reactor for the dry reforming of methane process configured in a simulation with the plug flow reactor, the reactor for the methanol formation process is configured in a simulation with the reactor equilibrium, and the reactor for the formation of acetic acid is configured in simulation with reactor conversion.

\subsubsection{Reactor for Synthesis Gas Formation}

Dry reforming of methane reaction was a reversible endothermic reaction, where an increase in temperature will increase the equilibrium conversion and the reaction rate so that it leads to a reaction towards the product, while the increase of reaction pressure will lead to a reaction towards the reactant.

The reaction occurs in the simulated reactor was nonisothermal, where the reactor's inlet and outlet temperatures were $900^{\circ} \mathrm{C}$ and $910^{\circ} \mathrm{C}$. The simulated reaction was also a non-isobaric reaction, where the reactor's inlet and outlet pressures were 1.4 bar and 1 bar. In this simulation, the optimum reactor volume was 471.2 $\mathrm{m}^{3}$ with $\mathrm{CO}_{2}$ conversion and $\mathrm{CH}_{4}$ conversion were $99.75 \%$ and $55.73 \%$ as shown in Figure 4 . Because the
$\mathrm{CO}_{2}$ was the limiting reactant, so the amount $45 \%$ of $\mathrm{CH}_{4}$ has not been converted in the reactor.

The effect of inlet temperature on reactor heating requirement is shown in Figure 5. The temperature in the reactor was set around $900^{\circ} \mathrm{C}$ according to thermodynamic analysis. Variations of inlet temperature were $700^{\circ} \mathrm{C}, 800^{\circ} \mathrm{C}$, and $900^{\circ} \mathrm{C}$. The lower temperature of the inlet, more heat requirement that must be supplied to the reactor, so the inlet temperature was better at $900^{\circ} \mathrm{C}$.

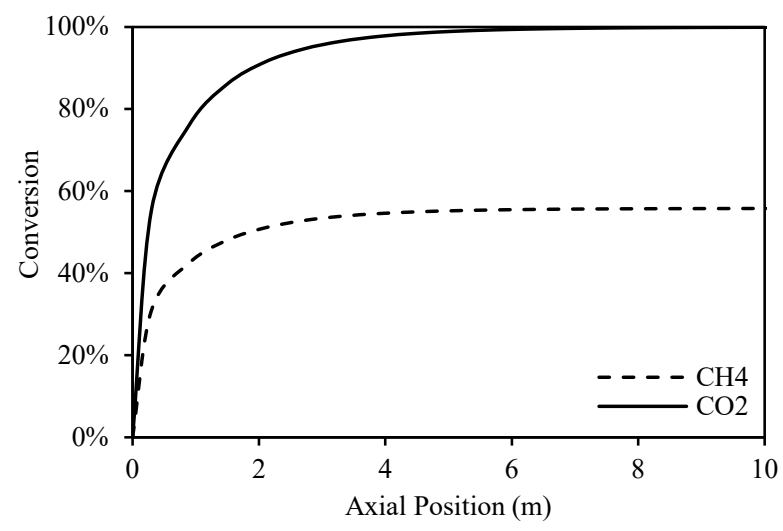

Figure 4. Conversion of $\mathrm{CO}_{2}$ and $\mathrm{CH}_{4}$ along the reactor in the DRM process

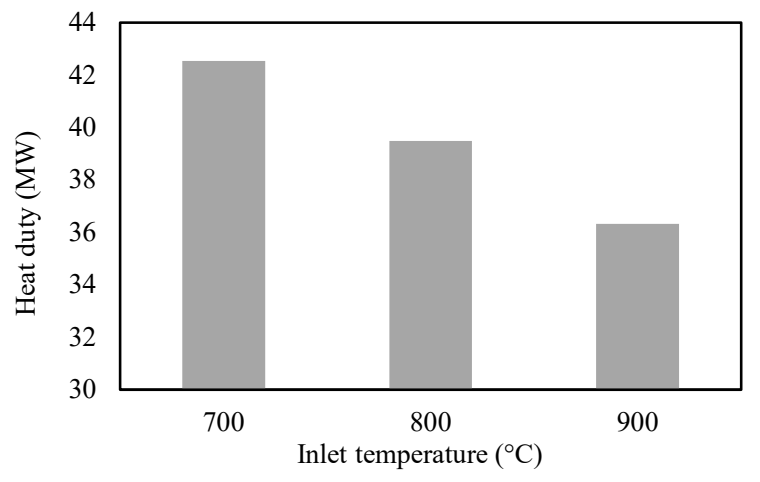

Figure 5. The effect of inlet temperature on reactor heating requirement at $910^{\circ} \mathrm{C}$ outlet temperature

\subsubsection{Reactor for Methanol Formation}

The process of methanol formation uses a tube cooled reactor with a copper-zinc-alumina based catalyst. This reactor was a vessel with many tubes maintaining the reaction temperature due to its reversible exothermic reaction. This reactor configuration was modeled in the simulation as an equilibrium reactor. The reaction that occurs only follows equation (5) because the amount of $\mathrm{CO}_{2}$ and $\mathrm{H}_{2} \mathrm{O}$ is so small, so other reactions involving this component were ignored. The reaction that occurs in the simulated reactor was non-isothermal because there was a decreased pressure of 1 bar so the reactor's inlet and outlet temperature were $152^{\circ} \mathrm{C}$ and $151^{\circ} \mathrm{C}$. $\mathrm{CO}$ and $\mathrm{H}_{2}$ conversion in this reactor were $98.43 \%$ and $62.65 \% . \mathrm{H}_{2}$ conversion was not optimal due to the amount of $\mathrm{CO}$ was not proportional to the amount of $\mathrm{H}_{2}$ in the reactor, where the amount of $\mathrm{H}_{2}$ was almost three times of $\mathrm{CO}$. 


\subsubsection{Reactor for Acetic Acid Formation}

The acetic acid formation uses a trickle bed reactor with a complex rhodium-based catalyst. The feed phase of the reactor was gas and liquid. The configuration of this reactor was modelled in the simulation as a reactor conversion. The reaction that occurs in this reactor follows equation (8), where the reaction was an irreversible exothermic reaction. The reaction in the simulated reactor was isothermal so the reactor's inlet and outlet temperature had the same temperature around $175^{\circ} \mathrm{C}$. The reactant conversion in the reactor was set to $99 \%$.

Table 2. Stream summary of acetic acid production from $\mathrm{CO}_{2}$ and $\mathrm{CH}_{4}$ using the developing model in ASPEN HYSYS.

\begin{tabular}{|c|c|c|c|c|c|c|c|c|}
\hline Stream & 1 & 2 & 3 & 4 & 5 & 6 & 7 & 8 \\
\hline Total flow, kmol/h & 500 & 500 & 1880 & 1880 & 2874 & 2874 & 558.4 & 2316 \\
\hline Temperature, ${ }^{\circ} \mathrm{C}$ & 600 & 600 & 375 & 900 & 910 & 401 & 47.8 & 47.8 \\
\hline Pressure, bar & 1.5 & 1.5 & 1.5 & 1.4 & 1.0 & 1.0 & 1.0 & 1.0 \\
\hline $\mathrm{CH}_{4}$ & 500.0 & 0.0 & 867.4 & 867.4 & 370.1 & 370.1 & 0.0 & 370.1 \\
\hline $\mathrm{CO}_{2}$ & 0.0 & 500.0 & 500.0 & 500.0 & 0.0 & 0.0 & 0.0 & 0.0 \\
\hline $\mathrm{CO}$ & 0.0 & 0.0 & 8.5 & 8.5 & 1005.8 & 1005.8 & 502.9 & 502.9 \\
\hline $\mathrm{H}_{2}$ & 0.0 & 0.0 & 448.3 & 448.3 & 1440.1 & 1440.1 & 0.0 & 1440.1 \\
\hline $\mathrm{H}_{2} \mathrm{O}$ & 0.0 & 0.0 & 0.0 & 0.0 & 2.8 & 2.8 & 0.0 & 2.8 \\
\hline $\mathrm{CH}_{3} \mathrm{OH}$ & 0.0 & 0.0 & 55.5 & 55.5 & 55.5 & 55.5 & 55.54 & 0.0 \\
\hline $\mathrm{CH}_{3} \mathrm{COOH}$ & 0.0 & 0.0 & 0.0 & 0.0 & 0.0 & 0.0 & 0.0 & 0.0 \\
\hline Stream & 9 & 10 & 11 & 12 & 13 & 14 & 15 & 16 \\
\hline Total flow, kmol/h & 2316 & 2316 & 2316 & 1258 & 69.5 & 1327 & 1327 & 1327 \\
\hline Temperature, ${ }^{\circ} \mathrm{C}$ & 763.8 & 533.2 & 151.9 & 150.9 & 150.9 & 150.9 & 88.6 & 49.9 \\
\hline Pressure, bar & 50.5 & 50.0 & 49.5 & 48.5 & 48.5 & 48.5 & 3.5 & 3.0 \\
\hline $\mathrm{CH}_{4}$ & 370.1 & 370.1 & 370.1 & 368.5 & 1.6 & 370.1 & 370.1 & 370.1 \\
\hline $\mathrm{CO}_{2}$ & 0.0 & 0.0 & 0.0 & 0.0 & 0.0 & 0.0 & 0.0 & 0.0 \\
\hline $\mathrm{CO}$ & 502.9 & 502.9 & 502.9 & 8.5 & 0.0 & 8.5 & 8.5 & 8.5 \\
\hline $\mathrm{H}_{2}$ & 1440.1 & 1440.1 & 1440.1 & 450.8 & 0.6 & 451.4 & 451.4 & 451.4 \\
\hline $\mathrm{H}_{2} \mathrm{O}$ & 2.8 & 2.8 & 2.8 & 1.9 & 0.8 & 2.8 & 2.8 & 2.8 \\
\hline $\mathrm{CH}_{3} \mathrm{OH}$ & 0.0 & 0.0 & 0.0 & 427.9 & 66.5 & 494.4 & 494.4 & 494.4 \\
\hline $\mathrm{CH}_{3} \mathrm{COOH}$ & 0.0 & 0.0 & 0.0 & 0.0 & 0.0 & 0.0 & 0.0 & 0.0 \\
\hline Stream & 17 & 18 & 19 & 20 & 21 & $22-$ & $22+$ & 23 \\
\hline Total flow, kmol/h & 441.9 & 885.2 & 885.2 & 885.2 & 558.4 & 1000 & 1000 & 1028.2 \\
\hline Temperature, ${ }^{\circ} \mathrm{C}$ & 29.8 & 29.8 & 12.6 & 12.6 & 215 & 50.4 & 47.7 & 46.7 \\
\hline Pressure, bar & 3.0 & 3.0 & 1.5 & 1.5 & 3.5 & 3.0 & 3.0 & 3.0 \\
\hline $\mathrm{CH}_{4}$ & 0.7 & 369.4 & 369.4 & 369.4 & 0.0 & 0.7 & 0.7 & 2.2 \\
\hline $\mathrm{CO}_{2}$ & 0.0 & 0.0 & 0.0 & 0.0 & 0.0 & 0.0 & 0.0 & 0.0 \\
\hline $\mathrm{CO}$ & 0.0 & 8.5 & 8.5 & 8.5 & 502.8 & 502.8 & 502.8 & 524.1 \\
\hline $\mathrm{H}_{2}$ & 0.1 & 451.3 & 451.3 & 451.3 & 0.0 & 0.1 & 0.1 & 0.3 \\
\hline $\mathrm{H}_{2} \mathrm{O}$ & 2.7 & 0.0 & 0.0 & 0.0 & 0.0 & 2.8 & 2.8 & 2.9 \\
\hline $\mathrm{CH}_{3} \mathrm{OH}$ & 438.5 & 55.9 & 55.9 & 55.9 & 55.5 & 494.0 & 494.0 & 498.7 \\
\hline $\mathrm{CH}_{3} \mathrm{COOH}$ & 0.0 & 0.0 & 0.0 & 0.0 & 0.0 & 0.0 & 0.0 & 0.0 \\
\hline Stream & 24 & 25 & 26 & 27 & 28 & 29 & 30 & 31 \\
\hline Total flow, kmol/h & 1028.2 & 1028.2 & 0.0 & 534.5 & 534.5 & 501.6 & 32.9 & 496.8 \\
\hline Temperature, ${ }^{\circ} \mathrm{C}$ & 175 & 175 & 175 & 175 & 30 & 34.8 & -182.2 & 136 \\
\hline Pressure, bar & 2.5 & 1.7 & 1.7 & 1.7 & 2 & 2 & 2 & 1.7 \\
\hline $\mathrm{CH}_{4}$ & 2.2 & 2.2 & 0.0 & 2.2 & 2.2 & 0.0 & 2.2 & 0.0 \\
\hline $\mathrm{CO}_{2}$ & 0.0 & 0.0 & 0.0 & 0.0 & 0.0 & 0.0 & 0.0 & 0.0 \\
\hline $\mathrm{CO}$ & 524.1 & 524.1 & 0.0 & 30.4 & 30.4 & 0.0 & 30.4 & 0.0 \\
\hline $\mathrm{H}_{2}$ & 0.3 & 0.3 & 0.0 & 0.3 & 0.3 & 0.0 & 0.3 & 0.0 \\
\hline $\mathrm{H}_{2} \mathrm{O}$ & 2.9 & 2.9 & 0.0 & 2.9 & 2.9 & 2.9 & 0.0 & 2.9 \\
\hline $\mathrm{CH}_{3} \mathrm{OH}$ & 498.7 & 498.7 & 0.0 & 5.0 & 5.0 & 5.0 & 0.0 & 0.3 \\
\hline $\mathrm{CH}_{3} \mathrm{COOH}$ & 0.0 & 0.0 & 0.0 & 493.7 & 493.7 & 493.7 & 0.0 & 493.7 \\
\hline Stream & 32 & 33 & 34 & 35 & 36 & 37 & 38 & 39 \\
\hline Total flow, kmol/h & 4.8 & 496.8 & 152.2 & 152.2 & 9.9 & 23.0 & 23.0 & 23.0 \\
\hline Temperature, ${ }^{\circ} \mathrm{C}$ & 74.8 & 30 & 74.9 & 74.9 & -182.2 & -182.2 & -161.6 & -161.6 \\
\hline Pressure, bar & 1.5 & 1 & 3.5 & 3.5 & 2 & 2 & 3.5 & 3.5 \\
\hline $\mathrm{CH}_{4}$ & 0.0 & 0.0 & 0.0 & 0.0 & 0.7 & 1.6 & 1.6 & 1.6 \\
\hline $\mathrm{CO}_{2}$ & 0.0 & 0.0 & 0.0 & 0.0 & 0.0 & 0.0 & 0.0 & 0.0 \\
\hline $\mathrm{CO}$ & 0.0 & 0.0 & 0.0 & 0.0 & 9.1 & 21.3 & 21.3 & 21.3 \\
\hline $\mathrm{H}_{2}$ & 0.0 & 0.0 & 0.0 & 0.0 & 0.1 & 0.2 & 0.2 & 0.2 \\
\hline $\mathrm{H}_{2} \mathrm{O}$ & 0.0 & 2.9 & 0.4 & 0.4 & 0.0 & 0.0 & 0.0 & 0.0 \\
\hline $\mathrm{CH}_{3} \mathrm{OH}$ & 4.7 & 0.3 & 151.8 & 151.8 & 0.0 & 0.0 & 0.0 & 0.0 \\
\hline $\mathrm{CH}_{3} \mathrm{COOH}$ & 0.0 & 493.7 & 0.0 & 0.0 & 0.0 & 0.0 & 0.0 & 0.0 \\
\hline
\end{tabular}




\subsection{Process simulation}

The study of acetic acid simulation process was applied for $496.8 \mathrm{kmol} / \mathrm{h}$. The results are shown in terms of material balances, chemical compositions, temperatures and pressure streams in Table 2. The gas feed used were $500 \mathrm{kmol} / \mathrm{h}$ for each $\mathrm{CH}_{4}$ and $\mathrm{CO}_{2}$. The acetic acid product in this process has a purity of $99.38 \%$ with a concentration of $500 \mathrm{ppm}$ methanol, and a moisture content of 5,700 ppm, where the products produced meet the desired product specifications. The heating and cooling requirements needed in the process are shown in Table 3.

Heaters are needed in the process of producing acetic acid in plug flow reactors (PFR-100) and distillation systems (T-101). The furnace is needed in plug flow reactors (PFR-100) because the temperature used to heat the reactor (PFR-100) is quite high due to the endotherm reaction, so to maintain the reaction temperature requires heating from outside. A reboiler is needed in the distillation system (T-101) to boil and vaporize some liquid of the fluid. The heating requirements of the system needed were around 40.7 MW or 4.7 MMBtu per ton of acetic acid.

Table 3. The heating and cooling needs of the processing system

\begin{tabular}{clc}
\hline \multirow{2}{*}{ Heater/Cooler } & $\begin{array}{c}\text { Energy duty } \\
\text { (MW) }\end{array}$ \\
\hline \multirow{3}{*}{ Heater } & Furnace (Q1) & -36.4 \\
\cline { 2 - 3 } & Reboiler (Q11) & -4.3 \\
\hline & Reactor ERV-100 (Q5) & 14.08 \\
\cline { 2 - 3 } Reactor CRV-100 (Q8) & 16.93 \\
\cline { 2 - 3 } Cooler & Cooler E-100 (Q4) & 8.24 \\
\cline { 2 - 3 } & Cooler E-104 (Q9) & 5.13 \\
\cline { 2 - 3 } & Cooler E-105 (Q12) & 1.44 \\
\cline { 2 - 3 } & Separator V-100 (Q7) & 1.64 \\
\cline { 2 - 3 } Cooler E-101 (Q9) & 4.073 \\
\cline { 2 - 3 } & Condenser (Q12) & 0.002 \\
\hline
\end{tabular}

The cooling requirements needed in the production of acetic acid were used in the methanol formation reactor (ERV-100), acetic acid formation reactor (CRV-100), cooling on the compressor and pump, cooling on the condenser in the distillation column (T-101), etc.

The coolant needed in the reactor is used to cool the ERV-100 and CRV-100 reactors caused by the exothermic reaction where the reactor temperature will be higher. The increase of reaction temperature in the exothermic reaction will reduce the yield of the product, so to maintain the reaction temperature, an external cooler was needed. The reactor used in this process uses a cooling jacket on the outside of the reactor, the cooling media used was LP steam generation. In addition to LP steam generation, cooling water was used in the cooler (E$104)$, cooler (E-105), and cooler in the separator (V-100).
Meanwhile, the air was used to cooler (E-101) and condenser. The heating requirements of the system needed were around $51.53 \mathrm{MW}$.

\section{Conclusion}

Simulation of acetic acid production from $\mathrm{CO}_{2}$ and $\mathrm{CH}_{4}$ using Aspen HYSYS v.10 obtains production of 496.8 $\mathrm{kmol} / \mathrm{h}$ from $500 \mathrm{kmol} / \mathrm{h}$ of $\mathrm{CH}_{4}$ and $500 \mathrm{kmol} / \mathrm{h}$ of $\mathrm{CO}_{2}$. The acetic acid product had a purity of $99.38 \%$ with a concentration of $500 \mathrm{ppm}$ methanol, and a moisture content of 5,700 ppm, where the products according to the desired specifications. The energy integration unit used in the simulation was a heat exchanger unit, furnace, reboiler, and cooler. The heating unit was required 4.7 MMBtu per ton of acetic acid and the cooler unit was required a cooling load of $51.53 \mathrm{MW}$.

\section{Acknowledgements}

The authors would like to acknowledge the Ministry of Research, Technology, and Higher Education of Indonesia, with the number of research 1101a/11.C06/KU/2019 for financially supporting this research

\section{References}

Abdulrasheed, A., A. A. Jalil, Y. Gambo, Ibrahim, M. Ibrahim, H. U. Hambali, and M. Y. S. Hamid; "A Review on Catalyst Development for Dry Reforming of Methane to Syngas: Recent Advances," Renewable and Sustainable Energy Reviews, 108, 175-193 (2019)

Balasubramanian, P., I. Bajaj, and M. M. F. Hasan; "Simulation and Optimization of Reforming Reactors for Carbon Dioxide Utilization Using both Rigorous and Reduced Models," Journal of $\mathrm{CO}_{2}$ Utilization, 23, 80-104 (2018)

Foppa, L., M-C. Silaghi, K. Larmier, and A. ComasVives; "Intrinsic Reactivity of $\mathrm{Ni}, \mathrm{Pd}$ and Pt Surfaces in Dry Reforming and Competitive Reactions: Insights from First Principles Calculations and Microkinetic Modeling Simulations," Journal of Catalysis, 343, 196-207 (2016)

Graaf, G. H., E. J. Stamhuis, and A. A. C. M. Beenackers; "Kinetics of Low-Pressure Methanol Synthesis," Chemical Engineering Science, 43, 3185-3195 (1988)

Jarrell, M. S. and B. C. Gates; "Methanol Carbonylation Catalyzed by a Polymer-Bound Rhodium (I) Complex," Journal of Catalysis, 40, 255-267 (1975)

Knifton, J. F.; "Syngas Reactions: Acetic Acid from Synthesis Gas," Journal of Catalysis, 96, 439-453 (1985)

Luyben, W. L: "Design and Control of the Dry Methane Reforming Process," Industrial and Engineering Chemistry Research, 53, 14423-14439 (2014)

Richardson, J. T. and S. A. Paripatyadar; "Carbon Dioxide Reforming of Methane with Supported Rhodium," Applied Catalysis, 61, 293-309 (1990)

Sumartono; "Pengolahan Gas Limbah Proyek Gas Natuna," (in Malay) Jurnal Teknologi Lingkungan, 1, 1 (2000) 